\title{
Comparative Study on Sino-American Higher Design Art Education
}

\author{
Jimin Qiao ${ }^{1}$ \\ Shangdong Woman's University \\ Jinan-China \\ qiaojimin1217@163.com
}

\author{
Chongli Zhao ${ }^{2}$ \\ Shangdong Woman's University \\ Jinan-China \\ qiaojimin1217@163.com
}

\begin{abstract}
Higher design art education is the fundamental force for pushing creative industry. The USA is one of the most developed countries for art education. There is a large difference of Sino-American higher design art education because of their different cultural traditions and specific national conditions. This paper aims to rethink the problem existing in Chinese educational system through comparatively analyzing the design art educations between China and the USA, to figure out the gap, confirm our objective and keep moving forward during Chinese design art education construction and development.
\end{abstract}

Keywords-Sino-American; design art; higher education; teaching mode

\section{INTRODUCTION}

The scale of running a school for China higher education leaped to the first according to the statistic data in 2006. Higher design art education is an very important part among the higher educational system. However, economic development and social progress is not equal to the cultural progress. Both the popular aesthetic education and professional design art education present different randomness. Due to the catalog revision of newest undergraduate program by Ministry of Education in 2012, art was separated from literature to be the $13^{\text {th }}$ category. Design art

major correspondingly becomes the first revised subject.

For a long time, China design community has trended to employ comparative mode to criticize domestic design by foreign design theory. Therefore, designers or relative staffs contact many exotic design works and concepts. They always imitate and pursues, which is not strictly considered as original creation, but reflects the difference existing in creative industries between China and outside world. As an open-oriented nation blessing with multi cultures, the USA is the first powerful country for creative industry, as well as one of the most developed nations for design art education. With vivid individuality and feature, American design art education is incontrovertibly on the leading position of western educational thought and system, it also keeps a follow up with the social development to formulate and change its educational mode, course design, talent training and other aspects. This paper tries to compare the differences on Sino-American design art educations in the field of student resource recruiting, teaching staffs' construction, educational

Fund project-“"Study on Relationship between Contemporary Design Talent's Cultivation and Creative Industry Development", Youth Fund Project of Humanities and Social Science Research by Ministry of Education in 2011, project No.:11YJC760118 form, teaching evaluation and so on, to rethink the problem we have in China design art education and figure out solution, which is with significant reference value.

\section{RECRUITING OF STUDENT RESOURCE}

Recently, China design art major has increasingly expanded, especially when it comes to 21 st century, art examination became a hot word with apparent Chinese character for college entrance examination. Many of the students, who are hopeless to enter into an university, often take their learning career off in new directions midcourse. They will participate in art exam after several months or weeks' painting training to major in design. What the short-term art exam training can constrainedly establish is the understanding of basic sketch and gouache color, while the superior humanistic quality and learning consciousness cannot be acquired, not to mention cultivating the divergent and innovative thinking model. Plenty of the students even know nothing about design and have no interest in it, as a result, the thinking of a significant number of students are rigid and inflexible during the educational process.

In China, art examination is adopted by GCT and independent examination organized by college itself. Take Shandong province for example, January and February are art examination period each year except the provincial GCT. Those colleges opening to the whole country for students recruiting will set up testing centers in Ji Nan, Qing Dao, Zi Bo, WeiFang and other cities. Examines exhaustedly travel to and from between different test centers for examination. The examination content is similar in large: sketch painting(portrait and still life inclusive),paint from life(in addition to portrait and still life, plaster model maybe added) or color painting(it usually focus on a certain still life). It usually takes around 3 hours each test. Performance of Professional course and cultural course will be combined for entrance enrolls. Some colleges focus on specialized course, but some will pay more attention to comprehensive performance.

From the point of view for student resource cultivation, China has not attached too much importance to aesthetic education all the time that is why design art students lack accomplishment in aesthetic taste and artistic culture. While in the USA, the national aesthetic quality is comparatively higher. In Texas, there is a provision: it is a must for middle schools to open a compressive course, including two parts of 
content----focus on art and art exchange[1]. Such a course is popularized at different levels in primary schools and middle schools of different classes and types all over the USA, so the school doesn't need to worry about its students' aesthetic taste level although he or she hasn't carry out any professional art creation. Art colleges in USA hope their students with abundant background, so undergraduates need to take some entrance test on painting. But graduates don't need to have any art background indeed, on contrary, American colleges prefer non-art major students with profound idea of art. As a result, it is common to see that an undergraduate learning Spanish successfully applied for oil painting graduate, or someone who major in psychology turned to graduate of digital media.

In addition, most art students in the USA are actually interested in art. Rating system is carried out in American Art Colleges with a huge tuition. Especially for some topmost famous colleges whose tuition is nearly twice or higher than ordinary public university (tuition of Rhode Island Design College is twice as that of ordinary public university). Art learning can not guarantee a promising future, so students without a great interest in art would not choose it. Since it is expensive, most students would work hard, but not drift along, in the hope of getting a maximum productive effect by means of huge tuition.

\section{TEACHING STAFFS CONSTRUCTION AND TEACHING ATMOSPHERE}

China colleges of arts usually bring in teaching staffs by recruiting openly towards the whole society. However, they focus more on the evaluation criteria for applicant's title, educational background and degree, which ensure the hired teaching staffs' good educational background at a certain level, but can not guarantee the applicant's professional quality. Especially for those young teachers who directly pass an entrance examination for position after graduation, they just wander from a school to another school, without complete design construction ability and independent design practical ability. Compared with the recruiting mode for department director of Chinese government, it is more independent for American teacher employment, but it has a higher requirement for teacher's social practical ability during the recruiting.

In China, Teachers have to spend more time and take painstaking care to cultivate students' basic design ability due to the latter's' limited ability and comprehensive accomplishment. Otherwise, a lot of students with weak design basis will have difficulty in making progress in the later professional learning. Especially for the foundational course, teachers always have a stricter requirement for students, so that the teacher-oriented teaching mode becomes the main teaching way. While in the USA, there is a higher starting point and demand for art students who will have a good aesthetic taste and a stable art basis when they enter into college. The USA art colleges trend to build up a family-oriented model. Take Rhode Island Design College for example, communication way between teachers and students is fair and dialogical. Students neither have to agree with all their teacher's opinions, nor learn according to their teacher's suggestions. Students could not refuse all teacher's advices and demands without a reason, but try to convince and debate in the form of discussion. Teachers teach students in accordance of their aptitude when discussion, to formulate certain learning way and goal for each student. In American design art class, students have to learn through discussion participation, which is different from that in China where students hardly have communication each other, let alone discussion with teachers. This is related to the difference among student resource and ethnic character.

\section{Educational Form AND TEACHING Goals}

Generally speaking, the length of schooling for China higher education of art and design education is 4 years in undergraduate course, while it is 3 years in junior college. The curriculum can be divided into public courses, basic courses and professional courses; furthermore, the professional courses can be divided into compulsory courses and optional courses. Take undergraduate education as an example, there are 8 semesters in total and the course arrangement varies with the colleges and majors. In general, public courses and basic courses are arranged in the first 4 semesters; professional courses are mainly arranged in 5-7 semesters; and the last semester is focusing on graduation project and practice. After the study of periodic courses, the relevant scores will be given at the end of the course by the professional teachers according to the classroom performance and final assignment. The person with qualified score will get the credit; otherwise, he or she needs to restudy this course. From this, we can know that the educational system in China has rigorous logic from the formulation of goals to overall planning. All of these are achieved step by step.

The educational system of American higher education of art and design education is similar to that of China. The schooling will last 4 years in undergraduate course. The focus of its teaching goal is the combination of theory and practice, aiming to cultivate students with creative thinking and ability of solving problem. Take Auburn University as an example, each of its academic years will be divided into 3 semesters, that is, spring semester (from Jan. to May.), summer semester (from May. to Aug.), and fall semester (from Aug. to Dec.), and the total semesters will be 12 . The course arrangement is flexible and varies with colleges and majors. What the educational form emphasizing is the subtle influence of environment, not the training with direct target. More attention is paid to the construction of optional courses and a large number of optional courses for different majors can be provided for students to choose; even the cross-registration can be realized. E.g. the students of Rhode Island School of Design (RISD) and Brown University (an Ivy League) can share the course, which means that a person majoring in graphic design in RISD can also take anthropology courses as his or her optional courses in Brown University. In this way, the disadvantage - lack of humanities and science education caused by professionalization in arts academy, will be avoided. Therefore, a more relaxed space and flexible time can be provided by American art and design education to the students to look for learning styles suitable to them. 


\section{Cultural Environment}

The cultural environment in China higher education of art and design education is relatively weak. Take culture and art activities as an example, the organization intensity and form of art activities organized by students are relatively substantial. In most cases, the culture and art activities on campus are organized by associations, and the form is not diversified, thus leading to a poor active participation. In other words, under Chinese educational form, the artistic accomplishment of students is generally lower, as a result of which the artistic atmosphere in Chinese universities is insufficient[2]. While in America, several of masterful art associations have been established in many universities, the members of which are art lovers not professionals. With diverse activity forms, the art activities will be arranged regularly, including the performance of the art groups with high level; art lecture or concert of scholar and celebrity; drama and art exhibition as well as movie appreciation. Each theme has its own characteristic, thus the requirements of different artistic appreciation can be satisfied[2].

\section{TEAChing Evaluation}

The teaching evaluation method for China art and design education is comparatively subjective. Its main standard for evaluation is based on the classroom performance and final assignment, that is to say, the grade is give by the instructor through his her subjective judgment, as a result, the students always pay attention to the final scores and ignore the gain and loss during the learning process. In addition, the single evaluation process will lead to the deficiency of communication between teachers and students.

In most cases, the form for handing assignments in American academy of arts is "critiques". At the end of the semester, the critiques will be carried out for each course, which means that each student shall introduce his or her works and accept everyone's comment and question before all other students (selecting this course), instructor and visiting artists. Furthermore, the question proposed is always very incisive, which requires the student has clear thought and confidence towards his or her works; only in this way can the "unkind" quizzer be convinced. Moreover, the communication between teachers and students or among students and participation degree in classroom discussion are also involved in the standard for evaluation[3].

\section{CUltural ENVIRONMENT}

There is a difference on Sino-American design art education because of their different cultural traditions and national conditions. The USA has developed a suitable scientific educational system, from whom we shall learn a lot. For China higher design art education, we should examine ourselves with a foresight, open and pluralistic eye and mind, to form a design art educational system based on our national condition, and further to train design art talents with spirit of exploring, innovation, cooperation and development.

\section{REFERENCES}

[1] Luo Haiou. The Open, Diverse and Comprehensive Art Education [J]. Educational Research. 2003.1

[2] Wu Qi. Shen Lili. A Comparative Study of Chinese and American College Art Education and Culture Environment [J]. Innovation Shenyang Anthology. (B) 2009. 8

[3] $\mathrm{Yu}$ Fang. The Comparison of Contemporary Sino-America Art Education [J]. Market Weekly. Finance Forum. 2004. 11 